新形質米のゲルコンシステンシー

$$
\text { 山崎賀久 }{ }^{*} \cdot \text { 大坪研一 }{ }^{* *} \cdot \text { 岩崎哲也 }{ }^{* * *}
$$

\title{
Gel Consistency of New Characteristic Rice Cultivars
}

\author{
Yoshihisa Yamazaki* ${ }^{*}$, Ken-ichi Ohtsubo ${ }^{* *}$ and Tetsuya Iwasaki ${ }^{* * *}$ \\ *Aomori Agricultural Products Processing Center, Yanagisawa, \\ Inuotose, Rokunohe-machi, Kamikita-gun, Aomori 033 \\ ** National Food Research Institute, Ministry of Agriculture, \\ (Present: Hokuriku National Agricultural Experiment \\ Station, Ministry of Agriculture, Forestry and Fisheries, \\ 1-2-1 Inada, Joetsu-shi, Niigata 943-01) \\ *** National Food Research Institute, Ministry of Agriculture, \\ Forestry and Fisheries, 2-1-2 Kannondai,
} Tsukuba-shi, Ibaraki 305

\begin{abstract}
Amylography, an important medium for evaluating eating quality, has such faults that is expensive machine, a sample size and measuring time. Gel consistency is often determined instead of amylography as a simplified method, by IRRI and other laboratories. In this study, gel consistency and amylography were measured on twelve samples. Modification on the standard method was required for determining gel consistency of "New characteristic rices" which have the novel characters as the Japonica rices. From the fact that the gel consistency showed high correlation to the amylography, the correlation of gel consistency to eating quality was suggested. Good eating quality of Sasanishiki from its large gel consistency, and poor eating quality of Hoshiyutaka from its small gel consistency were predicted.

(Received Jul. 18, 1991)
\end{abstract}

アミログラフィーは米の品質評価の重要な方法の一つ であるが、機械の価格や、測定時間，サンプル量などに 難点があり，必ずしも十分に利用されていない。

ゲルコンシステンシーの測定はアミログラフィーの代

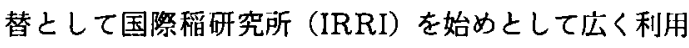
されており，両者の高い相関が実証されているが〉, こ れはインデカ、ジャポ二カを含めた広範囲の品質の米を 対象としたので，日本の米については狭い範囲の数値に 収まってしまって評価には役立たない。

本仾究は, 農林水産省の総合研究「需要应大のための 新形質水田作物の開発」の一部として行われたもので,
国内数か所の試験場で育成された新形質米についで2, 大ざっぱな区分け，あるいはランク付けができるように， ゲルコンシステンシーの測定条件を変更しようとしたも ので, アミログラフィーとの相関を確認すると同時にア ルカリ崩壊度についても測定を行った。

\section{実 臨 方 法}

\section{1. 供試材料}

供試した 1988 年産粳および糯米を Table 1 に示した. これらの供試材料玄米を佐竹製作所製研削式精米機で淿 精歩留 $90 \%$ に捣精した，得られた白米をリッチェ社製

*青森県農産物加工指導センター（宁033 青森県上北郡六戸町犬落瀨柳沢 91）

**農林水産省食品総合研究所（現在：農林水産省北陸農業試験場 T943-01 新潟県上越市稲田 1-2-1)

*** 震林水産省食品総合研究所（干305 茨城県つくば市観音台 2-1-2） 
Table 1 New characters of the rice samples

\begin{tabular}{ll}
\hline \multicolumn{1}{c}{ Variety } & \multicolumn{1}{c}{ New characters } \\
\hline Hokkai 240 & Large grain \\
Hokkai 269 & Gaiant embryo grain \\
Hokkai 270 & Aromatic \\
Douhoku 43 & Low amylose \\
Hokuriku 129 & Slightly long grain \\
Hokuriku 130 & Large grain \\
Sasanishiki & Common Japonica \\
Hoshiyutaka & High amylose \\
Nipponbare & Common Japonica \\
(NARC & \\
Nipponbare & Typical Japonica \\
(Ibaraki) & (standard) \\
Toumochi 396 & Colored waxy \\
Chugokumochi 119 & High yeild waxy \\
\hline
\end{tabular}

*NARC: National Agricultural Research Center

超遠心粉砕機で粉砕し，試料米粉を調製した. 別途, こ の粉砕力法で得られり米粉の粒度を検討したところ 48 メッシュ通過程度であった.

供試米粉の水分は試料間で $11.7 \sim 14.0 \%$ （平均 13.1 \%)の変動があり，試料間の条件を一定にするため水分 $13 \%$ に換算した量の米粉（以下水分 $13 \%$ という） ある い水分 $0 \%$ に換算した量の米粉（以下乾物換算という） を試験に用いた。

これらの供試材料の一般成分, テクスチャ一, 官能検 查については荒川ら゙゙により報告されている.

\section{2. アミログラム}

ブラベンダー社のアミログラフ（ビスコグラフ）装置 Pt 100 型を使用した，撹拌はパドル式を用い，試料濃 度 $8 \%$ で定法 ${ }^{4)}$ に従い試験を行った，すなわち，乾物換 算 $40 \mathrm{~g}$ の米㸮に蒸留水を加えて総量を $500 \mathrm{~g}$ とした。 温度条件は開始温度が $30^{\circ} \mathrm{C}$, 昇温速度 $1.5^{\circ} \mathrm{C} /$ 分で $93^{\circ} \mathrm{C}$ まで昇温し，10 分問この温度を保持した後， $1.5^{\circ} \mathrm{C} /$ 分 で $33^{\circ} \mathrm{C}$ まで冷却した，当初最終温度を $30^{\circ} \mathrm{C}$ とする予定 であったが, 冷却水の不調で $33^{\circ} \mathrm{C}$ 以下は不安定であっ

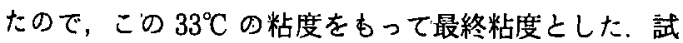
験は供試材料 12 種のうち粫米 2 種については省略し, 粳米 10 種について試験を行った.

\section{3.アルカリ崩壊度}

LITTLE ら ${ }^{5)}$ の報告に従い，白米を希アルカリ水溶液 に浸清し，一定時間後の米粒の膨潤度，崩壊度を観察で

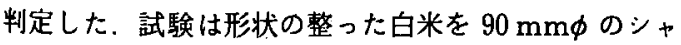

レーに 6 粒入れ，水酸化力リウム水溶液 $30 \mathrm{~m} l$ を入れ 行ったが, LITTLE らの試験条件では供試材料のほとん どが崩壊してしまうので，予備試験により，アルカリ浸 清条件を水酸化カリウム水溶液灙度 $1.2 \%(\mathrm{~W} / \mathrm{V}), 4$ ${ }^{\circ} \mathrm{C} ， 24$ 時問 ${ }^{6)}$ として試験を行った。崩壊程度を次の 8 段階に分け判定した。

$0:$ 米粒がまったく崩壊しない。

$1:$ 米粒が少し膨張する.

$2:$ 米粒が少し崩壊する.

3: 米粒が半分崩壊して周囲に粉状の環ができる.

4 : 米粒が崩壊して周囲の粉状の環が広がる.

$5:$ 米粒が崩壊して白い綿状になる。

6: 米粒が崩壊して半透明の綿状になる。

$7:$ 米粒が崩壊して透明な綿状になる。

4. ゲルコンシステンシー

CAGAMPANG ら”の報告に従いゲルコンシステンシー の予備試験を行い，さらに今回の供試材料に適するよう に条件を決定した。

予備試験は原報告に準じて米粉 $100 \mathrm{mg}$ （水分 13\%） を試験管 $(15 \mathrm{~mm} \phi \times 105 \mathrm{~mm})$ に入れ，さらに 0.025 $\%(\mathrm{~W} / \mathrm{V})$ チモールブルー含有 $95 \%$ エ タノール水溶液 を $0.2 \mathrm{ml}$ 入れ，試験管ミキサーで擋找し，さらに 0.2 $\mathrm{N}$ 水酸化力リウム水溶液を $2 \mathrm{ml}$ 入れ試験管ミキサー でよく擋拌する．この試験管を沸滕水浴中で 8 分間還流 加熱し， 5 分間室温放置後， 15 分間水水で邻却する.こ の試験管を方眼紙上に水平におき，60 分後に試験管の 底からゲルの先端までの長さを測定した。

予備試験の結果ゲルの固さが柔らかすぎ供試材料間の 差が判然としなかったため, $150 \mathrm{~mm}$ の試験管を使用 しゲルを固くする次の 2 方法で試験条件を検討した.

（1）水酸化カリウム水溶液濃度はそのままで, 米粉量 を $100 \mathrm{mg}$ 加ら $110 \mathrm{mg}, 120 \mathrm{mg}$ (水分 $13 \%$ ）に増加 させる ${ }^{7}$.

（2）米粉量はそのままで，水酸化カリゥム水溶液濃度 を $0.2 \mathrm{~N}$ から $0.15 \mathrm{~N}, 0.1 \mathrm{~N}$ に下げる.

\section{実験結果および考察}

\section{1. アミログラム}

アミログラフィーの結果を Table 2 に示す. 最高粘 度は「ササニシキ」が大きく、「北海 269 号」が小さか った. 最低粘度は「道北 43 号」,「北海 269 号」が小さ く，「北海 240 号」が大きい結果となった．米鈑の食味 と相関が高いと言われる最高粘度と最低粘度との差（ブ レークダウン）は「ササニシキ」が最大で「北海 240 号」 
Table 2 Characteristics of amylogram of "New Characteristic Rice"

\begin{tabular}{|c|c|c|c|c|c|c|c|c|}
\hline \multirow[b]{2}{*}{ Variety } & \multirow{2}{*}{$\begin{array}{l}\text { Pasting } \\
\text { temp. } \\
\left({ }^{\circ} \mathrm{C}\right)\end{array}$} & \multicolumn{7}{|c|}{ Amylograph viscosity* (Brabender units) } \\
\hline & & Peak & $\begin{array}{l}\text { Mini } \\
\text { mum }\end{array}$ & $\begin{array}{l}\text { Cooled } \\
\text { to } 50^{\circ} \mathrm{C} \\
\end{array}$ & $\begin{array}{l}\text { Cooled } \\
\text { to } 33^{\circ} \mathrm{C} \\
\end{array}$ & $\begin{array}{l}\text { Break } \\
\text { down }\end{array}$ & $\begin{array}{c}\text { Set } \\
\text { back }\end{array}$ & $\begin{array}{c}\text { Con } \\
\text { sistency }\end{array}$ \\
\hline Hokkai 240 & 80.0 & 420 & 355 & 645 & 760 & 65 & 225 & 405 \\
\hline Hokkai 269 & 85.5 & 120 & 10 & 310 & 445 & 110 & 190 & 435 \\
\hline Hokkai 270 & 63.0 & 390 & 260 & 600 & 720 & 130 & 210 & 460 \\
\hline Douhoku 43 & 64.5 & 345 & 140 & 305 & 410 & 205 & -40 & 270 \\
\hline Hokuriku 129 & 70.0 & 550 & 250 & 530 & 635 & 300 & -20 & 385 \\
\hline Hokuriku 130 & 66.0 & 560 & 275 & 530 & 635 & 285 & 110 & 360 \\
\hline Sasanishiki & 70.5 & 630 & 280 & 615 & 720 & 350 & -15 & 440 \\
\hline Hoshiyutaka & $.64: 0$ & 300 & 210 & 550 & 640 & 90 & 250 & 430 \\
\hline Nipponbare (NARC) & 69.0 & 530 & 255 & 600 & 705 & 275 & 70 & 450 \\
\hline Nipponbare (Ibaraki) & 76.5 & 495 & 255 & 580 & 690 & 240 & 85 & 435 \\
\hline
\end{tabular}

* Break down $=$ Peak viscosity - Minimum viscosity

Set back $=$ Cooled to $50^{\circ} \mathrm{C}$ viscosity - Peak viscosity

Consistency $=$ Cooled to $33^{\circ} \mathrm{C}$ viscosity - Minimum viscosity

が最小であった.

これらのアミログラム特性值で注目されるのは「北海 269 号」であり，粳米としては最高粘度と最低粘度が極 端に小さく他の材料と異なるアミログラムを示した.

\section{2. アルカリ崩壊度}

アルカリ崩壊度試験の結果を Table 3 に示した．粳 米に比較し糯米が崩壊しにくい傾向が認められた，粳米 間では北海系統と「ホシユタカ」が崩壊度の大きいグル 一プ, 北陸系統と「ササニシキ」が崩壊度の小さいグル ープ,「道北 43 号」と「日本晴」が中間程度のグループ に分類された。

\section{3. ゲルコンシステンシー}

米粉量、アルカり濃度とゲルコンシステンシーの関係 をTable 4 に示した. 静置 60 分後のゲルコンシステン シーが $90 \mathrm{~mm}$ を越えたものはゲルが被状になり，30 $\mathrm{mm}$ を下回るものに米粉が一部未糊化のものがあった ことから，安定なゲルをつくる条件として，供試材料の ゲルコンシステンシーが $30 \mathrm{~mm} \sim 90 \mathrm{~mm}$ の範囲に分 布する条件が望ましいと考元られた。供試粳米を主体に 試験条件を検討した結果

（1）水酸化カリウム濃度を $0.2 \mathrm{~N}$ として米粉量を变 えた場合，米粉量は $110 \mathrm{mg}$ と $120 \mathrm{mg}$ の中間の 115 $\mathrm{mg}$ （水分 $13 \% ）$ が適当と思われた．水分 $13 \%$ 含有の 米粉 $115 \mathrm{mg}$ は乾物に換算すると $100 \mathrm{mg}$ になるため, 水分補正するときの条件が分加りやすい乾物換算 100 $\mathrm{mg}$ を試験条件とした.
Table 3 Alkali spreading value of "New Characteristic Rice"

\begin{tabular}{lc}
\hline \hline \multicolumn{1}{c}{ Variety } & $\begin{array}{c}\text { Alkali } \\
\text { spreading } \\
\text { value }\end{array}$ \\
\hline Hokkai 240 & 6.2 \\
Hokkai 269 & 6.3 \\
Hokkai 270 & 6.5 \\
Douhoku 43 & 4.2 \\
Hokuriku 129 & 2.2 \\
Hokuriku 130 & 3.5 \\
Sasanishiki & 3.8 \\
Hoshiyutaka & 6.0 \\
Nipponbare (NARC) & 4.2 \\
Nipponbare (Ibaraki) & 4.8 \\
Toumochi 396 & 3.3 \\
Chugokumochi 119 & 2.8 \\
\hline
\end{tabular}

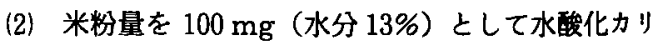
ウム濃度を变えた場合，水酸化カリウム浱度は $0.15 \mathrm{~N}$ の条件が適当であった。

この 2 測定条件で静置 30 分後, 60 分後のゲルコンシ ステンシーを測定した結果を Table 5 に示した. 静置 30 分後, 60 分後とも測定可能であったが，ゲルコンシ ステンシーの大きいあのは 30 分後，小さいあのは 60 分 後の方が供試材料間の差が明確であった。 
Table 4 Effects of sample weight and alkali concentration on gel hardness

\begin{tabular}{|c|c|c|c|c|c|c|}
\hline \multirow{3}{*}{ Variety } & \multicolumn{6}{|c|}{ Gel consistency (mm) } \\
\hline & \multicolumn{3}{|c|}{$0.2 \mathrm{~N}-\mathrm{KOH}$ Solution ${ }^{\mathrm{a})}$} & \multicolumn{3}{|c|}{$100 \mathrm{mg}$ Rice flour ${ }^{\mathrm{b}}$} \\
\hline & $100 \mathrm{mg}$ & $110 \mathrm{mg}$ & $120 \mathrm{mg}$ & $0.1 \mathrm{~N}$ & $0.15 \mathrm{~N}$ & $0.2 \mathrm{~N}$ \\
\hline Hokkai 240 & 61 & 49 & 41 & 26 & 37 & 66 \\
\hline Hokkai 269 & 69 & 56 & 46 & 28 & 49 & 74 \\
\hline Hokkai 270 & 89 & 67 & 50 & 47 & 57 & 69 \\
\hline Douhoku 43 & 102 & 77 & 68 & 35 & 61 & 96 \\
\hline Hokuriku 129 & 103 & 81 & 56 & 49 & 73 & 82 \\
\hline Hokuriku 130 & 104 & 80 & 67 & 50 & 67 & 101 \\
\hline Sasanishiki & 101 & 84 & 71 & 40 & 73 & 101 \\
\hline Hoshiyutaka & 53 & 40 & 30 & 27 & 31 & 59 \\
\hline Nipponbare (NARC) & 84 & 75 & 60 & 53 & 71 & 107 \\
\hline Nipponbare (Ibaraki) & 98 & 81 & 63 & 36 & 63 & 76 \\
\hline Toumochi 396 & 131 & 117 & 111 & 116 & 128 & 122 \\
\hline Chugokumochi 119 & 137 & 115 & 113 & 111 & 123 & 126 \\
\hline
\end{tabular}

Sample weight was converted into moisture content of $13 \%$.

The gel of ${ }^{\text {a) }}$ and ${ }^{\text {b) }}$ were spread at $23^{\circ} \mathrm{C}, 21^{\circ} \mathrm{C}$ respectively.

Table 5 Gel consistency of "New Characteristic Rice"

\begin{tabular}{|c|c|c|c|c|}
\hline \multirow{3}{*}{ Variety } & \multicolumn{4}{|c|}{ Gel consistency ( $\mathrm{mm}$ ) } \\
\hline & \multicolumn{2}{|c|}{ Dry matter $100 \mathrm{mg}^{\mathrm{a}}$} & \multicolumn{2}{|c|}{$0.15 \mathrm{~N}-\mathrm{KOH}^{\mathrm{b})}$} \\
\hline & $30 \mathrm{~min}$ & $60 \mathrm{~min}$ & $30 \mathrm{~min}$ & $60 \mathrm{~min}$ \\
\hline Hokkai 240 & 31 & 36 & 39 & 44 \\
\hline Hokkai 269 & 41 & 47 & 47 & 52 \\
\hline Hokkai 270 & 49 & 56 & 58 & 63 \\
\hline Douhoku 43 & 63 & 69 & 64 & 67 \\
\hline Hokuriku 129 & 73 & 80 & 67 & 72 \\
\hline Hokuriku 130 & 63 & 70 & 69 & 71 \\
\hline Sasanishiki & 61 & 70 & 70 & 74 \\
\hline Hoshiyutaka & 27 & 30 & 27 & 31 \\
\hline Nipponbare (NARC) & 58 & 67 & 63 & 68 \\
\hline Nipponbare (Ibaraki) & 62 & 71 & 66 & 71 \\
\hline Toumochi 396 & 97 & 104 & 105 & 122 \\
\hline Chugokumochi 119 & 102 & 118 & 104 & 123 \\
\hline \multicolumn{5}{|c|}{$\begin{array}{l}\text { The length of gel was measured } 30 \mathrm{~min} \text { and } 60 \mathrm{~min} \text { after laid horizontally } \\
\text { at } 21^{\circ} \mathrm{C} \text {. } \\
\text { a) Sample } 100 \mathrm{mg} \text { (as dry matter), } 0.2 \mathrm{~N}-\mathrm{KOH} \text { solution, reflux time } 10 \mathrm{~min} \\
\text { b) Sample } 100 \mathrm{mg} \text { (as } 13 \% \text { moisture content), } 0.15 \mathrm{~N}-\mathrm{KOH} \text { solution, reflux } \\
\text { time } 13 \mathrm{~min}\end{array}$} \\
\hline
\end{tabular}


Table 6 Correlation coefficients ammong physicochemical properties of "New Characteristic Rice"

\begin{tabular}{lccc}
\hline \multirow{2}{*}{ Amylograph properties } & $\begin{array}{c}\text { Alkali spreading } \\
\text { value }\end{array}$ & \multicolumn{2}{c}{ Gel consistency } \\
\cline { 3 - 4 } & 0.278 & $\begin{array}{c}\text { Dry matter } \\
100 \mathrm{mg}^{\text {a) }}\end{array}$ & $\begin{array}{c}0.15 \mathrm{~N}-\mathrm{KOH} \\
\text { Soln }\end{array}$ \\
\hline Pasting temp. & $-0.707^{* *}$ & -0.222 & -0.183 \\
Peak viscosity & -0.205 & $0.644^{*}$ & $0.639^{*}$ \\
Minimum viscosity & -0.012 & 0.094 & 0.108 \\
Viscosity cooled to $50^{\circ} \mathrm{C}$ & -0.032 & -0.051 & -0.002 \\
Viscosity cooled to $33^{\circ} \mathrm{C}$ & $0.880^{* * *}$ & -0.032 & 0.002 \\
Break down & $0.847^{* *}$ & $0.889^{* * *}$ & $0.868^{* *}$ \\
Set back & 0.219 & $-0.867^{* *}$ & $-0.797^{* *}$ \\
Consistency & -0.151 & -0.081 \\
\hline
\end{tabular}

The length of gel was measured $60 \mathrm{~min}$ after laid horizontally at $21^{\circ} \mathrm{C}$.

a) Sample $100 \mathrm{mg}$ (as dry matter), $0.2 \mathrm{~N}-\mathrm{KOH}$ solution, reflux time $10 \mathrm{~min}$

b) Sample $100 \mathrm{mg}$ (as $13 \%$ moisture content), $0.15 \mathrm{~N}-\mathrm{KOH}$ solution, reflux time $13 \mathrm{~min}$

Number of samples correlated shown in parenthesis, ${ }^{*}=p<0.05,{ }^{* *}=p<0.01,{ }^{* * *}=p$ $<0.001(\mathrm{n}=10)$.

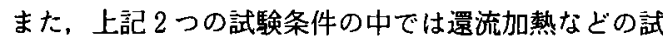
験作業面で水酸化カリウム濃度 $0.2 \mathrm{~N}$, 試料米粉量 100 $\mathrm{mg}$ (乾物換算) の方が適当であった。

このように，原報告の条件を変更した場合，還流加熱 時に試験管の内容物が吹きこばれたり，できたゲルが不 均一になる場合がある，吹きこぼれを防ぐためには試験 管の長さを $105 \mathrm{~mm}$ から $150 \mathrm{~mm}$ に変える，またゲル を均一にするためには還流加熱時間を 8 分間加ら 10 分 間（米粉量を増加した場合）おるいは 13 分間（アルカ り濃度を薄くした場合）に延長する対策が有効であった。

\section{4. 諸特性値の相互関係}

糯米 2 種を除いた粳米 10 種のアミログラム、アルカ リ崩壊度, ゲルコンシステンシーの相関関係を Table 6 に示した. 米の食味と関係が深いと言われている゙ ログラムのブレークダゥン，セットバックとアルカリ崩 壊度, ゲルコンシステンシーとの間に高い相関関係が認 められた。

ゲルコンシステンシーはこれまで我が国で米の品質評 価に適用された報告例はないが，高価な機械を使用し 1 日あたりの試験点数の非常に少ないアミログラフィーと 高い町関関係にあり，簡易で処理点数の多い手法として 評価される. 本試験は，变動幅の比較的大きい新形質米 について行われたものであり，大きな変動を同一条件で 検討することを前提として行われた．このため，今回の 試験条件では「ササニシキ」,「日本晴」など変動幅の小
さい従来の日本稲閒ではその差は明確ではないので，こ れらの差を見きわめるためには別途試験条件を検討する 必要がある。また，一般に異なる環境で栽培された米 （稲）の評価をする場合，その差が品種間差なのか，栽 培環境の差なのか判然としない場合が多いが，今回の供 試材料も新形質米の個々の育成地で栽培されたものを使 用したので，この点は判然とはしない，しかし，品種育 成などの変動幅が大きく，多数の試験材料を扱う育成試 験地等では，簡便で処理点数が多く，必要な試料間のわ ずかなゲルコンシステンシーは（手間のかかる分析をす る必要の有無を判定するだけでも）有効な手段と思われ ろ.

\section{要約}

簡易な米品質評価手法であるアルカリ崩壊度、ゲルコ ンシステンシーの 2 うの試験方法を新形質米に適用し た.

（1）粳米のアルカリ崩壊度は北海系統と「ホシュタカ」 が大きく、北陸系統と「ササニシキ」が小さかった，糯 米は粳米より崩罣度が小さかった。

（2）ゲルコンシステンシーの試験条件は「水酸化カリ ウム濃度 $0.2 \mathrm{~N}$, 試料米粉量 $100 \mathrm{mg}$ (乾物換算)」が 適当であった。

(3) アルカリ崩壊度, ゲルコンシステンシーとアミロ グラム特性値との間に高い相関が認められ，新形質米の 
簡易な品質評価手法と考えられる.

(4) 通常のジャポニカ種の評価のためには上記の試験 条件では不充分であり，別途条件を検討する必要がある。

本試験は，農林水産省技術会議の「新形質米」プロシ ェクト予算で行われた。

本試験の試料を提供頂いた各育成試験場に感謝いたし ます。

\section{文献}

1) Cagampang, G.B., Perez, C.M. and Juliano, B.O.: J. Sci. Food. Agric., 24, 1589-1594 (1973).
2）横尾政雄：農林水産技術研究ジャーナル，13， 50-57 (1989).

3）茫川榇彦・佐川弘子・小川紀男・大坪研一・喿崎 哲也 : 日本食品上業学会第 37 回大会講演集, p. 44, 東京 (1990).

4）農林省食糧研究所：食糧技術普及シリーズ 7 号, 「米の品質之眝藏, 利用」, p. 21 (1969).

5) Little, R.R., Hilder. G.B. and Dawson, E.H. : Cereal Chem., 35, 111-126 (1958).

6) 倉沢文夫 - 早川利朗 - 伊賀上郁夫 : 栄養と食糧, 12, 396-372 (1960).

7) Juliano, B.O.: J. Jap. Soc. Starch Sci., 29, 305-317 (1982).

8）竹生新治郎 - 渡辺正造 - 杉本貞三 - 酒井藤敏 - 谷 口喜廣 : 激粉科学, 30,333-341 (1983).

(平成 3 年 7 月 18 日受理) 